\title{
LETRAMENTO DIGITAL E TUTORIA NO AMBIENTE DA EDUCAÇÃO A DISTÂNCIA: UM ESTUDO À GUISA DE ESTADO DA ARTE
}

\author{
Ricardo Viana Velloso ${ }^{1}$ \\ Luzia Bueno ${ }^{2}$
}

Resumo: Este artigo tem por objetivo abordar as relações ente o tutor virtual e suas competências em programas de educação a distância, considerando seu domínio no campo do letramento e do letramento digital, com lastro nos estudos publicados na ANPED. À guisa de estado da arte, realizou-se o levantamento das publicações do período entre 2009 e 2013, circunscritas aos seguintes grupos de trabalho: GT08 Formação de Professores; GT09 Trabalho e Educação; GT10 Alfabetização, Leitura e Escrita; GT11 Política de Educação Superior e GT16 Educação e Comunicação. Os resultados mostram a predominância de pesquisas qualitativas, que reconhecem, na sua maioria, a relevância da atuação do tutor em EAD, sobretudo quanto a sua função mediadora. Mostram ainda que, a despeito da recorrente preocupação com as competências do tutor para o trânsito no ambiente virtual, as referências a competências relacionadas ao letramento digital são relegadas a segundo plano em favor de outras preocupações: implicações das TIC para o trabalho docente; tutoria e precarização do trabalho; (sub)utilização das TIC no ensinoaprendizagem etc. Os resultados evidenciam, por fim, a necessidade de mais pesquisas envolvendo o letramento digital do tutor, tendo em vista inclusive suas implicações políticas para a formação e para o trabalho docente em EAD.

Palavras-chave: Professor tutor - EAD. Competência didática. Letramento tecnológico.

Doutorando em Educação da Universidade São Francisco (USF), campus Itatiba (SP)

Doutora em Linguística Aplicada pela PUC-SP e Professora do Programa de Mestrado e Doutorado em Educação da Universidade São Francisco, campus Itatiba (SP) 


\title{
DIGITAL LITERACY AND TUTORING IN THE DISTANCE EDUCATION ENVIRONMENT:
}

\author{
A STATE OF THE ART STUDY
}

\begin{abstract}
This article aims to address the relationships between the virtual tutor and his/her competencies in distance education programs, considering it in the field of literacy and digital literacy, as reflected in the studies published in ANPED. By way of state of the art, there was a survey of publications between 2009 and 2013, circumscribed to the following working groups: GT08 Teacher Training; GT09 Work and Education; GT10 Literacy, Reading and Writing; GT11 Policy of Higher Education; and GT16 Education and Communication. The results show the predominance of qualitative research, which recognize mostly the relevance of the tutor's role in distance education, especially as its mediating function. They still show that, despite the applicant's concern with the tutor skills for transit in the virtual environment, references to skills related to digital literacy are relegated to the background in favor of other concerns: implications of ICT for teaching; tutoring and job insecurity; (under)utilization of ICT in the teaching-learning process etc. The results show, finally, the need for more research involving tutor's digital literacy with a view to their political implications for training and for teaching in distance education.
\end{abstract}

Keywords: Tutor in distance education. Didactic competence. Technological literacy.

\section{ALFABETIZACIÓN DIGITAL Y LA FORMACIÓN EN EL ÁMBITO EDUCATIVO A DISTANCIA: UN ESTUDIO SOBRE EL ESTADO DE LA TÉCNICA GUISE}

Resumen: Este artículo tiene como objetivo abordar las relaciones entre el tutor virtual y los programas de educación a distancia, considerando su dominio en el campo de la alfabetización y alfabetización digital, apoyado en estudios publicados en ANPED. Con esa finalidad se hizo un levantamiento de publicaciones entre 2009 y 2013, circunscripto a los siguientes grupos de trabajo: Formación de Profesores GT08; GT09 Trabajo y Educación; GT10 Alfabetización, Lectura y Escritura; Política GT11 de Educación Superior y Educación GT16 y Educación y Comunicación. Los resultados muestran el predominio de investigaciones cualitativas, que reconocen, en su mayor parte, la relevancia del papel del tutor en la educación a distancia, sobre todo por la función mediadora. Muestran también que, a pesar de la reiterada preocupación en relación a la competencia del tutor en el ámbito virtual, relacionada a la alfabetización digital, las referencias a las habilidades para la alfabetización digital son relegadas a un segundo plano en favor de otras preocupaciones como: implicaciones de las TIC para la enseñanza; tutoría y la precariedad; (Sub) el uso de las TIC en la enseñanza-aprendizaje, etc. Los resultados muestran, por último, la necesidad de investigar mejor el grado de dominio del tutor de alfabetización digital, con el fin de incluir sus implicaciones políticas para la formación y para la enseñanza de la educación a distancia.

Palabras clave: Tutor en EAD. Habilidades de interacción. Alfabetización tecnológica. 


\section{Introdução}

Com a incorporação crescente das tecnologias da informação e comunicação às práticas pedagógicas no ambiente da educação presencial ou a distância, o letramento digital e a tutoria ganham a cena como importantes componentes na efetivação das práticas pedagógicas. No caso da modalidade educacional a distância, em particular, ao tutor virtual compete, dentre outros, mediar as interações em favor da construção colaborativa do conhecimento e da prática da aprendizagem autônoma, o que demanda competências específicas, imbricadas com o letramento e o letramento digital da parte do tutor.

Nesse sentido, examinar as abordagens que se vêm fazendo na seara acadêmica acerca do letramento digital como dimensão atinente às competências interacionais, insertas no rol constitutivo do perfil do tutor, tendo em vista suas atribuições nos programas de Ead, torna oportuno que se proceda a um levantamento de estudos contemporâneos que tratam o tema.

Por essa razão, o presente estudo apresenta, à guisa de abordagem do estado da arte, o exame dos trabalhos publicados nos últimos cinco anos, pela Associação Nacional de Pós-Graduação e Pesquisa em Educação (ANPED), insertos nos Grupos de trabalho: GT08 Formação de Professores; GT09 Trabalho e Educação; GT10 Alfabetização, Leitura e Escrita; GT11 Política de Educação Superior e GT16 Educação e Comunicação. A delimitação dos grupos mencionados decorre do fato de seus respectivos escopos suscitarem a possibilidade de contemplarem estudos envolvendo o letramento e o letramento digital, assim como a atividade docente própria do tutor, sujeito sempre presente nos programas de educação a distância.

O levantamento dos estudos ora proposto é antecedido de abordagem que busca a compreensão dos conceitos atinentes a letramento e letramento digital, assim como acerca da tutoria em cursos/programas de educação na modalidade a distância. 


\section{Letramento e Letramento Digital}

\section{Letramento e Prática Social}

As práticas sociais da leitura e da escrita ao longo do tempo assumiram diferentes significados e valores para as diversas sociedades, tendo em vista suas crenças, concepções, assim como as relações de poder. A busca de compreensão de tais práticas e de suas múltiplas conotações convida inevitavelmente a uma incursão no universo do que o pesquisador estadunidense James Gee (apud STREET, 2014), passou a designar como Novos Estudos do Letramento (New Literacy Studies). Numa referência a esses estudos, Street assinala que:

\footnotetext{
A tendência tem sido no rumo de uma consideração mais ampla do letramento como uma prática social e numa perspectiva transcultural. Dentro dessa perspectiva, uma mudança importante foi a rejeição por vários autores da visão dominante do letramento como uma habilidade 'neutra', técnica, e a conceitualização do letramento, ao contrário, como uma prática ideológica, envolvida em relações de poder e incrustada em significados e práticas culturais específicos (STREET, 2014, p. 17).
}

Tais estudos, extrapolando a visão de letramento como circunscrito ao indivíduo, confere-lhe conotação e valor social (e político), trazendo, como forte componente de abordagem, nas pesquisas sobre o tema, o olhar etnográfico. É um movimento de extrapolação, que Street (1995) aponta como reconhecimento de um letramento ideológico em superação ao historicamente constituído letramento autônomo. Enquanto este remete a uma concepção comprometida com a apreensão da técnica, pelo indivíduo, tomando a leitura e a escrita como instrumentos cujo domínio determina a ascensão social, o outro compromete-se com as dimensões social e cultural, com diferentes significados nos diferentes contextos, em que se instauram múltiplos eventos e práticas sociais situadas (STREET, 2014, p. 19).

Em sentido amplo, pode-se dizer que as pesquisas sobre letramento têm por escopo a escrita, sua apropriação e uso, bem como suas funções, significados e efeitos, quer para o sujeito social tratado individualmente, quer para as sociedades. Pelas diversas conotações atribuídas ao letramento, é possível tomar o termo como polissêmico, o que se evidencia nos múltiplos e, não raro, conflitantes, significados que lhe são atribuídos. 
Kleiman (2010, p. 17) nos lembra que, "pela complexidade e variação dos tipos de estudos que se enquadram nesse domínio, podemos perceber a complexidade do conceito." Tendo em vista, no entanto, o fato de que a escrita, tanto na perspectiva da produção quanto da recepção, processa-se nos meios sociais, predominantemente como fator de interação entre os atores e grupos, e ainda o fato de que tais interações são permeadas por relações de poder, consideramos procedente, ante os múltiplos conceitos, conceber o letramento com lastro no que preconizam Street (2014), Kleiman (2009) e Marcuschi (2001).

Para Street (2014) o letramento está associado ao contexto em que se dá, devendo ser percebido inclusive nas suas dimensões sociais, na perspectiva do letramento ideológico, que "não tenta negar a habilidade técnica ou os aspectos cognitivos da leitura e da escrita, mas sim entendê-los como encapsulados em todos culturais e em estruturas de poder". (STREET, 2014, p. 172).

Kleiman (1995, p. 19), por sua vez, assevera que: "podemos definir hoje o letramento como um conjunto de práticas sociais que usam a escrita, como sistema simbólico e como tecnologia, em contextos específicos, para objetivos específicos."

Por fim, Marcuschi enfatiza que:

Hoje não é mais possível investigar questões relativas ao letramento, isto é, às práticas da leitura e da escrita na sociedade, permanecendo apenas no aspecto linguístico sem uma perspectiva crítica, uma abordagem etnograficamente situada e uma inserção cultural das questões nos domínios discursivos. (MARCUSCHI, 2001, p. 25).

Nesse diapasão, passamos a tratar o letramento, no presente trabalho, como fenômeno e prática social do uso da escrita, tendo em vista os contextos em que se processa, as intencionalidades com que se compromete, assim como as relações de poder que perpassam as atividades interacionais entre os atores e entre estes e o universo que integram. Essa concepção torna inevitável conceber suas imbricadas relações com as dimensões culturais, sociais, econômicas e políticas, que se podem identificar em eventos e práticas de letramento.

Os eventos de letramento, para Heath, numa citação por Street (2014, p. 172), referem-se a situações em que a escrita assume papel fundante nas interações dos sujeitos, bem como nos seus processos interpretativos, constituídos em episódios observáveis. Nesse sentido, constituem recortes da vida social e das interações humanas 
em seu âmbito, que possibilitam exame mais detido. Pela sua imbricada relação com as práticas sociais de letramento, os eventos hão de ser percebidos no âmbito daquelas. Nessa perspectiva:

As práticas de letramento incorporam não só 'eventos de letramento', como ocasiões empíricas às quais o letramento é essencial, mas também modelos populares desses eventos e as preconcepções ideológicas que os sustentam. (STREET, 2014, p. 18).

Em síntese, os eventos de letramento constituem recortes das interações intersubjetivas, que decorrem das práticas sociais de letramento, guardando ambos relação dialógica, de modo que a compreensão das práticas implica a apreensão dos eventos, ao mesmo tempo em que o exame destes remete às práticas em que se inserem.

Ademais, por sua conotação social e política, o uso da escrita à luz dos Novos Estudos do Letramento traz implicações para as políticas públicas, para a educação e para as pesquisas afetas ao ensino e à aprendizagem. Nesse diapasão, o letramento "já é parte de uma relação de poder, e o modo como as pessoas 'se apropriam' dele é uma contingência de práticas sociais e culturais e não só de fatores pedagógicos e cognitivos." (STREET, 2014, p. 201)

Por sua abrangência e complexidade intrínseca e ainda em virtude de suas múltiplas conotações e dos contornos que assume nos diversos contextos sociais, o letramento aponta cada vez mais para a impossibilidade de um único termo conter todas as categorias e significados que emergem do uso social da escrita. Esse fato concita-nos a considerar a pluralidade própria do letramento, tornando, então, procedente falarmos em letramentos, no plural, ou multiletramentos.

\section{A Pluralidade do Letramento nos Múltiplos Contextos Sociais}

A concepção do letramento imbricada com a ideia de prática social do uso da escrita, relacionada com diferentes contextos (espaciais, temporais, históricos, culturais, políticos) faz emergirem adjetivações que identificam o letramento político, religioso, visual, digital etc., tornando procedente reconhecer múltiplos letramentos. Tais designações tentam abarcar variadas práticas situadas de uso da escrita.

Acerca desse cenário, Street (1984, p. 47) afirma que: 
Seria, provavelmente, mais apropriado referirmo-nos a "letramentos" do que a um único letramento, e devemos falar de letramentos, e não de letramento, tanto no sentido de diversas linguagens e escritas, quanto no sentido de múltiplos níveis de habilidades, conhecimentos e crenças, no campo de cada língua e/ou escrita.

Rojo considera que, na esteira da perspectiva ideológica:

Começa-se a reconhecer processos e práticas diferenciados entre diversas agências de letramento (família, igreja, escola, sindicatos etc.) e não são poucos os trabalhos comparativos entre grupos sociais, sociedades ou culturas que se desenvolveram a partir de então. [...] Portanto, diferentes práticas e contextos de letramento começam a ser investigados. Começa-se a pensar em letramentos. (ROJO, 2001, p. 67).

Soares (2002, p. 143-156), por seu turno, depois de assinalar, em relação ao letramento, que "não há uma diversidade de conceitos, mas diversidade de ênfases na caracterização do fenômeno", reconhece que "letramento é fenômeno plural, historicamente e contemporaneamente: diferentes letramentos ao longo do tempo, diferentes letramentos no nosso tempo".

No bojo da pluralidade dos usos da escrita e, em consequência, do letramento propriamente dito, seja em virtude dos contextos sociais ou das condições de produção da escrita, emerge o que contemporaneamente se vem designando como letramento digital.

\section{O Letramento Digital e Novas Possibilidades}

O advento desse tipo de letramento pode ser percebido como ressonância do que Dionísio considera, ao asseverar que:

Se as formas de interação entre os homens mudam de acordo com as necessidades de cada sociedade, se as formas de interação entre as pessoas são influenciadas pelo desenvolvimento tecnológico, o primeiro conceito que merece ser revisto é o conceito de letramento (DIONISIO, 2011, p. 137).

Nessa perspectiva, face os avanços das tecnologias da informação e da comunicação, outros modos de usos da escrita, outras referências de letramento são demandadas dos sujeitos para o trânsito nesse universo. Afinal, as formas de composição (hiper)textual trazem como marca expressiva a multimodalidade, na mobilização de 
recursos verbais e não-verbais, sonoros, imagéticos, associados de forma variada, numa deliberada complexificação dos textos e dos gêneros. Nesse sentido, ganha relevo o letramento digital, como possibilidade de inserção e trânsito na sociedade referida por Castells (2003) como a sociedade da informação e do conhecimento. Para a interação e integração a esse contexto, novas habilidades e competências hão de ser mobilizadas, mais precisamente na perspectiva do letramento digital, que, segundo Xavier:

Implica realizar práticas de leitura e escrita diferentes das formas tradicionais de letramento e alfabetização. Ser letrado digital pressupõe assumir mudanças nos modos de ler e escrever os códigos e sinais verbais e não-verbais, como imagens e desenhos, se compararmos às formas de leitura e escrita feitas no livro, até porque o suporte sobre o qual estão os textos digitais é a tela, também digital. (XAVIER, 2015, p. 2).

Corroborando essa percepção, instauram-se novas percepções e relações "entre escritor e leitor, entre escritor e texto, entre leitor e texto e até mesmo, mais amplamente falando, entre o ser humano e o conhecimento" (SOARES, 2002, p. 151).

\section{Educação A Distância, Tutoria e Outras Interações}

\section{Reorientação de Paradigmas na Modalidade EAD}

Com os avanços científicos e, em especial os tecnológicos, mais precisamente no campo da informação e da comunicação, novos paradigmas espaço-temporais, outros agenciamentos e novas estratégias interacionais vêm se instaurando.

$\mathrm{Na}$ esteira das mudanças perpetradas, ganha a cena progressivamente a modalidade de educação a distância, que se caracteriza, nos termos do Decreto Presidencial Decreto no 5.622 de 19 de dezembro de 2005, pela mediação dos processos de ensinoaprendizagem. Mais precisamente, o texto legal referido prescreve:

Art. 1o Para os fins deste Decreto, caracteriza-se a Educação a Distância como modalidade educacional na qual a mediação didático-pedagógica nos processos de ensino e aprendizagem ocorre com a utilização de meios e tecnologias de informação e comunicação, Associação Brasileira de Educação a Distância 86 RBAAD - Educação a distância: conceitos e história no Brasil e no mundo com estudantes e professores desenvolvendo atividades educativas em lugares ou tempos diversos. (BRASIL, 2005). 
Nesse contexto, os atores envolvidos na cena educacional veem-se ante o mister de ressituar-se, compreendendo e assumindo diferentes papéis, numa situação em que, superando a transmissão e recepção de informações, passam a se comprometer com novas relações com o conhecimento. $O$ aluno tende a assumir certo protagonismo no seu processo de cognição, enquanto o professor tende a ser demandado como o mediador. Nesse sentido,

O professor torna-se um animador da inteligência coletiva dos grupos que estão a seu encargo. Sua atividade será centrada no acompanhamento e na gestão das aprendizagens: o incitamento à troca dos saberes, a mediação relacional e simbólica, a pilotagem personalizada dos percursos de aprendizagem etc. (LÉVY, 2010, p. 173, grifo do autor).

Com essa complexificação de seu papel no ambiente da inteligência coletiva, o trabalho docente vê-se multifacetado e passa a envolver diferentes atores na sua composição, instaurando-se, nesse cenário, a polidocência, como resposta às especificidades da modalidade educacional a distância. Acerca desse conceito, é pertinente avaliar que:

Sob o modo de organização polidocente, o saber que seria detido por um único educador no ensino presencial é segmentado e distribuído a vários profissionais. Assim, na EaD, equivalendo à figura do professor da educação presencial, surgem categorias profissionais redefinidas: como o docenteconteudista, o docente-tutor (virtual e presencial), o docente projetista educacional (ou designer instrucional ou estrategista pedagógico), entre outras (MILL, 2010, p. 27-28).

\section{O Tutor e o Advento de Outras Interações}

Em relação ao tutor virtual, outros contornos e relevância se colocam, por implicar sua interação sistemática com o aluno no ambiente virtual de aprendizagem, a qual guarda imbricada relação com o nível de adesão do discente aos processos pedagógicos na modalidade a distância e ainda com seu grau de (in)sucesso no exercício de cognição. Ao tutor compete atuar em favor da motivação dos alunos no AVA, promovendo interações concorrentes para a construção colaborativa do conhecimento, que se dê de forma significativa para o aluno, instigando-o a perseverar na sua experiência de aprendizagem.

Para tanto, são demandadas do tutor virtual múltiplas competências, que requerem o conhecimento da proposta pedagógica com que está envolvido, bem como o perfil dos 
alunos com os quais irá interagir. Requer ainda o domínio dos conteúdos pertinentes, bem como dos recursos técnicos e didático-pedagógicos dos quais irá se valer para a mediação do processo ensino-aprendizagem.

No exercício de tais competências, é fundamental que o tutor virtual tenha especial capacidade de interação, que implica, inevitavelmente, considerar suas habilidades no tocante ao letramento e, mais especificamente, ao letramento digital, na medida em que as interlocuções demandam a mobilização de diferentes estratégias discursivas, para fazer frente à lógica hipertextual e multimodal, própria do ambiente virtual, complexificado, por excelência. Afinal, trata-se do ambiente em que:

O diálogo interativo ocupa papel central na aprendizagem, pois contribui para a (re)elaboração de significados gerados a partir das múltiplas vozes referidas em cada enunciação. A aprendizagem dialógica é um processo que promove o reposicionamento do sujeito no horizonte conceitual do outro e a apropriação de gêneros de discurso e atitudes científicas. (GIORDAN, 2006).

Nesse sentido, múltiplos são os desafios e variadas são as estratégias discursivas exigidas, para empreender ações prescritivas e didáticas em etapas instrucionais, práticas de mediação nos fóruns temáticos, exercícios de adesão e de estimulação em momentos de tergiversação dos alunos etc. Tais intervenções requerem a percepção dos processos e usos da escrita, inclusive com as peculiaridades que os caracterizam no ambiente virtual e, em especial, no ambiente virtual de aprendizagem, comprometido, portanto, com intencionalidades pedagógicas.

Sob essa perspectiva, pensar o perfil (e a formação) do tutor em atividade nos cursos/programas de educação a distância faz-se relevante, já que o (re)conhecimento de suas habilidades e competências, desenvolvidas no contexto do letramento e do letramento digital, podem ser determinantes para os processos e resultados em práticas pedagógicas no ambiente virtual de aprendizagem.

Portanto, estudos nessa seara tornam-se cada vez mais necessários (e urgentes) para desvelar o quadro que se tem na atualidade e para que possam ser pensadas e implementadas políticas e programas de formação, os quais valorizem o tutor e o letramento (digital, inclusive) de que seja ele portador. Essa percepção remete à pertinência de se levantar os estudos, na seara acadêmica, que versem sobre letramento 
digital como uma das competências insertas no rol constitutivo do perfil do tutor, tendo em vista suas atribuições nos programas de Ead.

\section{À Guisa de Estado da Arte}

\section{Definindo o Corpus}

O estudo ora apresentado considerou o exame dos trabalhos publicados no lapso temporal entre 2009 e 2013, isso é, nos últimos cinco anos, pela Associação Nacional de Pós-Graduação e Pesquisa em Educação (ANPED), insertos nos Grupos de trabalho: GT08 Formação de Professores; GT09 Trabalho e Educação; GT10 Alfabetização, Leitura e Escrita; GT11 Política de Educação Superior e GT16 Educação e Comunicação. A definição dos Grupos de Trabalho observou o contorno temático destes, cujos escopos apontavam para a possibilidade de conterem estudos atinentes aos objetos de interesse, abordando, portanto, o letramento e o letramento digital, assim como a atividade docente própria do tutor, sujeito sempre presente nos programas de educação a distância.

Para a seleção dos trabalhos, foram adotados, como critérios, a presença, implícita ou explícita, de considerações sobre letramento e letramento digital, bem como referências, explícitas ou não, à tutoria ou ao tutor atuante em cursos/programas na modalidade educacional a distância. Tais referências poderiam ocorrer simultaneamente ou não, no mesmo trabalho. A identificação dos artigos implicou a apreciação dos títulos das publicações, em alguns casos; o exame do resumo, em outros casos; e ainda a verificação da íntegra dos textos, quando as pistas anteriores não se faziam conclusivas.

No âmbito dos referidos Grupos de Trabalho, no recorte temporal definido, procedeu-se, então, à seleção com lastro nos critérios (ou pistas) adotados. Resultaram, assim, 21 trabalhos, cujas abordagens perpassaram a docência, a formação inicial e continuada, o trabalho docente, habilidades e competências próprias do professor (tutor ou não), além de atribuições, saberes e habilidades para o trânsito nos ambientes de aprendizagem sustentados pelas tecnologias digitais. Por ser reduzido o número de trabalhos, ainda que sem a seleção mais refinada, é possível e pertinente apresentar uma síntese nos termos do quadro seguin 
Quadro 1- Trabalhos (2009/2013) que abordam docência, habilidades e competências do professor (tutor ou não)

\begin{tabular}{|c|c|c|}
\hline Título do trabalho & Autor & GT / ano \\
\hline $\begin{array}{c}\text { O computador na educação e a formação } \\
\text { docente: perspectivas de } \\
\text { professores dos anos iniciais do } \\
\text { ensino fundamental }\end{array}$ & $\begin{array}{l}\text { Analigia Miranda da } \\
\text { Silva }\end{array}$ & GT08/2013 \\
\hline $\begin{array}{c}\text { As tecnologias de base microeletrônica e a } \\
\text { intensificação do trabalho na pós- } \\
\text { graduação: novos aportes na relação } \\
\text { orientador-orientando }\end{array}$ & Lucídio Bianchetti & GT09/2013 \\
\hline $\begin{array}{c}\text { A comunicação e os saberes dos tutores } \\
\text { em educação a distância }\end{array}$ & $\begin{array}{l}\text { Thais P. Grutzmann } \\
\text { Mauro A. B. del Pino }\end{array}$ & GT16/2013 \\
\hline $\begin{array}{c}\text { Formar ou preparar para a docência no } \\
\text { ensino superior? Eis a questão }\end{array}$ & $\begin{array}{l}\text { Vanessa Therezinha } \\
\text { Bueno Campos }\end{array}$ & GT08/2012 \\
\hline $\begin{array}{l}\text { Trabalho, lugar e identidade profissional } \\
\text { docente: um estudo de caso em austin, } \\
\text { baixada fluminense }\end{array}$ & $\begin{array}{l}\text { Euler Oliveira C. da } \\
\text { Costa } \\
\text { Lilian Maria P. C. } \\
\text { Ramos }\end{array}$ & GT08/2012 \\
\hline $\begin{array}{l}\text { Novas tecnologias digitais da informação e } \\
\text { comunicação e o esino-aprendizagem de } \\
\text { língua portuguesa }\end{array}$ & $\begin{array}{l}\text { Roberta Varginha } \\
\text { Ramos Caiado }\end{array}$ & GT10/2012 \\
\hline $\begin{array}{c}\text { Reflexões sobre o perfil tecnológico dos } \\
\text { professores do núcleo de itabaianalsergipe } \\
\text { no curso de formação para PROUCA }\end{array}$ & $\begin{array}{c}\begin{array}{c}\text { Ronaldo Nunes } \\
\text { Linhares }\end{array} \\
\text { Simone de L. Ferreira } \\
\end{array}$ & GT16/2012 \\
\hline $\begin{array}{l}\text { Atividades de produção da docência: a } \\
\text { professoralidade universitária }\end{array}$ & $\begin{array}{c}\text { Ana Carla H. Powaczuk } \\
\text { Doris Pires V. Bolzan }\end{array}$ & GT08/2011 \\
\hline $\begin{array}{l}\text { Configuração do trabalho realizado no ead: } \\
\text { implicações para o campo educacional }\end{array}$ & $\begin{array}{c}\text { Valdelaine da R. Mend } \\
\text { es }\end{array}$ & GT09/2011 \\
\hline $\begin{array}{l}\text { A alfabetização e sua relação com o uso do } \\
\text { computador: o suporte digital como mais } \\
\text { um instrumento de ensino-aprendizagem }\end{array}$ & $\begin{array}{l}\text { Julianna Silva Glória } \\
\text { Isabel C. A. da S. Frade }\end{array}$ & GT10/2011 \\
\hline $\begin{array}{c}\text { Ead no sistema de educação superior: } \\
\text { questões para a agenda 2011-2020 }\end{array}$ & Stella C. D. Segenreich & GT11/2011 \\
\hline $\begin{array}{l}\text { Docência no ensino superior brasileiro: } \\
\text { representações de pós-graduandos de } \\
\text { instituições federais de ensino superior }\end{array}$ & Vanessa T. B. Campos & GT11/2011 \\
\hline $\begin{array}{l}\text { O professor coletivo na perspectiva do } \\
\text { trabalho docente da tutoria }\end{array}$ & $\begin{array}{c}\text { Roseli Zen Cerny } \\
\text { Andrea Brandão Lapa }\end{array}$ & GT16/2011 \\
\hline $\begin{array}{l}\text { Práticas de letramento digital no contexto } \\
\text { da inclusão de laptops educacionais }\end{array}$ & $\begin{array}{l}\text { Eliana M. do S. Soares } \\
\text { Carla Beatriz Valentini }\end{array}$ & GT16/2011 \\
\hline $\begin{array}{l}\text { Tecnologias e ações de formação na prática } \\
\text { docente }\end{array}$ & $\begin{array}{l}\text { Solange Mary Moreira } \\
\text { Santos Santos }\end{array}$ & GT16/2011 \\
\hline $\begin{array}{l}\text { Formação continuada em comunidade de } \\
\text { prática: conectividade e aprendizagem em } \\
\text { rede }\end{array}$ & $\begin{array}{c}\text { Maria Cristina } \\
\text { Lima Paniago Lopes }\end{array}$ & GT16/2011 \\
\hline $\begin{array}{c}\text { Sob o signo da convergência: reflexões } \\
\text { sobre o papel das mídias digitais interativas } \\
\text { na educação }\end{array}$ & Marcelo Sabbatini & GT16/2011 \\
\hline Impressões digitais e capital tecnológic & Rafael da Cunha Lara & GT16/2011 \\
\hline
\end{tabular}




\begin{tabular}{|c|c|c|}
\hline $\begin{array}{c}\text { lugar das tic na formação inicial de } \\
\text { professores }\end{array}$ & Elisa Maria Quartiero & \\
\hline $\begin{array}{c}\text { Formação para o uso das tecnologias } \\
\text { digitais de informação e comunicação } \\
\text { (tdic) nas licenciaturas presenciais das } \\
\text { universidades estaduais paulistas }\end{array}$ & $\begin{array}{c}\text { Rosemara Perpétua } \\
\text { Lopes } \\
\text { Monica Fürkotter }\end{array}$ & GT08/2010 \\
\hline $\begin{array}{c}\text { A formação dos professores para o uso das } \\
\text { tecnologias digitais nos gts formação de } \\
\text { professores e educação e comunicação da } \\
\text { anped - 2000 a 2008 }\end{array}$ & $\begin{array}{c}\text { Ezicléia Tavares Santos } \\
\text { Desvelando e explorando brechas das } \\
\text { políticas públicas em relação à inserção da } \\
\text { ead no ensino superior }\end{array}$ & $\begin{array}{c}\text { Stella Cecília Duarte } \\
\text { Segenreich }\end{array}$ \\
\hline
\end{tabular}

Fonte: Os autores.

Os trabalhos em apreço versam ora sobre competências digitais (letramentos?), ora sobre competências docentes, as quais são tratadas na perspectiva do trabalho ou da formação inicial e continuada.

Assim, refinando a busca e tendo em vista o interesse por trabalhos que têm por foco o tutor e o letramento (digital), foi possível excluir aqueles que se referem a pesquisas no âmbito da educação básica, uma vez que estes não tratam a atividade de tutoria, nem o tutor e seu perfil e competências. Foi possível ainda excluir trabalhos cujo foco recaiu sobre a formação (inicial ou continuada) de professores para a educação básica, que não remetiam à atuação do professor na graduação ou pós-graduação, nem do tutor em ambientes virtuais de aprendizagem. Igualmente, foram excluídos estudos que, embora tratando a EAD, não traziam abordagens relacionadas à tutoria e ou ao letramento, mas reflexões sobre políticas públicas, por exemplo.

Desse exercício, restaram nove trabalhos, cujos temas passamos a apontar no quadro seguinte. 
Quadro 2- Trabalhos com temas relacionados à EAD, tutoria e letramento digital

\begin{tabular}{|c|c|c|c|}
\hline Título do trabalho & GT / ano & Objetos temáticos & $\begin{array}{l}\text { Orientação } \\
\text { Metodológica }\end{array}$ \\
\hline $\begin{array}{l}\text { 1. As tecnologias de base } \\
\text { microeletrônica e a } \\
\text { intensificação do } \\
\text { trabalho na pós- } \\
\text { graduação: novos } \\
\text { aportes na relação } \\
\text { orientador- } \\
\text { orientando }\end{array}$ & $\begin{array}{c}\text { GT09/20 } \\
13\end{array}$ & $\begin{array}{l}\text { Incorporação das TIC na PG, } \\
\text { produção de conhecimento, } \\
\text { vida/trabalho dos envolvidos }\end{array}$ & $\begin{array}{l}\text { Pesquisa qualitativa } \\
\text { (entrevistas) }\end{array}$ \\
\hline $\begin{array}{l}\text { 2. A comunicação e os } \\
\text { saberes dos tutores } \\
\text { em educação a } \\
\text { distância }\end{array}$ & $\begin{array}{c}\text { GT16/201 } \\
3\end{array}$ & $\begin{array}{l}\text { Relação entre tutor e alunos } \\
\text { (processo comunicativo) em } \\
\text { curso graduação da UAB }\end{array}$ & $\begin{array}{l}\text { Pesquisa qualitativa } \\
\text { (entrevistas e } \\
\text { questionários) }\end{array}$ \\
\hline $\begin{array}{l}\text { 3. Formar ou preparar para } \\
\text { a docência no ensino } \\
\text { superior? Eis a questão }\end{array}$ & $\begin{array}{c}\text { GT08/201 } \\
2\end{array}$ & $\begin{array}{l}\text { Formação de professores e } \\
\text { docência no ensino superior: } \\
\text { sentidos, significados e } \\
\text { preparação aligeirada no ens. } \\
\text { superior }\end{array}$ & $\begin{array}{l}\text { Pesquisa } \\
\text { predominantement } \\
\text { e qualitativa } \\
\text { (entrevistas, } \\
\text { questionários e } \\
\text { observações) } \\
\end{array}$ \\
\hline $\begin{array}{l}\text { 4. Configuração do trabalho } \\
\text { realizado no ead: } \\
\text { implicações para o campo } \\
\text { educacional }\end{array}$ & $\begin{array}{l}\text { GT09/20 } \\
11\end{array}$ & $\begin{array}{c}\text { Implicações da expansão da EAD } \\
\text { sobre o trabalho docente, com } \\
\text { foco nos tutores }\end{array}$ & $\begin{array}{l}\text { Pesquisa qualitativa } \\
\text { (entrevistas) }\end{array}$ \\
\hline $\begin{array}{l}\text { 5. O professor coletivo na } \\
\text { perspectiva do trabalho } \\
\text { docente da tutoria }\end{array}$ & $\begin{array}{c}\text { GT16/201 } \\
1\end{array}$ & $\begin{array}{l}\text { Docência em EAD, professor } \\
\text { coletivo, tutores e sua } \\
\text { compreensão das funções no } \\
\text { processo }\end{array}$ & $\begin{array}{l}\text { Pesquisa qualitativa } \\
\text { (entrevistas e } \\
\text { questionários e } \\
\text { análise } \\
\text { documental) }\end{array}$ \\
\hline $\begin{array}{l}\text { 6. Impressões digitais e } \\
\text { capital tecnológico: o lugar } \\
\text { das tic na formação inicial } \\
\text { de professores }\end{array}$ & $\begin{array}{c}\text { GT16/201 } \\
1\end{array}$ & $\begin{array}{l}\text { Formação de professores para } \\
\text { atuação em contextos digitais }\end{array}$ & $\begin{array}{l}\text { Pesquisa quanti- } \\
\text { qualitativa } \\
\text { (questionários) }\end{array}$ \\
\hline $\begin{array}{l}\text { 7. Formação para o uso das } \\
\text { tecnologias digitais de } \\
\text { informação e comunicação } \\
\text { (tdic) nas licenciaturas } \\
\text { presenciais das } \\
\text { universidades estaduais } \\
\text { paulistas }\end{array}$ & $\begin{array}{c}\text { GT08/201 } \\
0\end{array}$ & $\begin{array}{l}\text { Tecnologias digitais na formação } \\
\text { inicial docente }\end{array}$ & $\begin{array}{l}\text { Pesquisa } \\
\text { quantitativa e } \\
\text { qualitativa (análise } \\
\text { de documentos: } \\
\text { projetos } \\
\text { pedagógicos) }\end{array}$ \\
\hline $\begin{array}{l}\text { 8. A formação dos } \\
\text { professores para o uso das } \\
\text { tecnologias digitais nos gts } \\
\text { formação de professores e } \\
\text { educação e comunicação da } \\
\text { anped - } 2000 \text { a } 2008\end{array}$ & $\begin{array}{c}\text { GT08/200 } \\
9\end{array}$ & $\begin{array}{c}\text { Estado da arte nos GT da ANPED, } \\
\text { entre } 2000 \text { e } 2008 \text {, em } \\
\text { referência a formação docente } \\
\text { para o uso das TIC }\end{array}$ & $\begin{array}{l}\text { Pesquisa qualitativa } \\
\text { (análise de } \\
\text { documentos: } \\
\text { comunicações } \\
\text { publicadas pela } \\
\text { ANPED }\end{array}$ \\
\hline $\begin{array}{l}\text { 9. Desvelando e explorando } \\
\text { brechas das políticas } \\
\text { públicas em relação à } \\
\text { inserção da ead no ensino } \\
\text { superior }\end{array}$ & $\begin{array}{c}\text { GT11/200 } \\
9\end{array}$ & $\begin{array}{c}\text { EAD, PROUNI, e cursos de } \\
\text { graduação tradicionais e de } \\
\text { formação tecnológica, práticas } \\
\text { pedagógicas e tutores }\end{array}$ & $\begin{array}{l}\text { Pesquisa } \\
\text { predominantement } \\
\text { e qualitativa } \\
\text { (análise de } \\
\text { documentos } \\
\text { institucionais, } \\
\text { normativos etc.) } \\
\end{array}$ \\
\hline
\end{tabular}

Fonte: Os autores. 
Apreciações Sobre a Orientação Metodológica dos Trabalhos

Os artigos selecionados, conforme os critérios já mencionados, remetem a pesquisas ou análise e discussão de resultados, sob a orientação predominantemente qualitativa. Apenas quatro dos trabalhos publicados não são exclusivamente identificados com a ótica qualitativa de pesquisa, envolvendo também a abordagem quantitativa, sem, contudo, prescindir daquela como a principal.

Como observa Flick (2009, p. 25):

Diferentemente da pesquisa quantitativa, os métodos qualitativos consideram a comunicação do pesquisador em campo como parte explícita da produção de conhecimento, em vez de simplesmente encará-la como uma variável a interferir no processo. A subjetividade do pesquisador, bem como daqueles que estão sendo estudados, tornam-se parte do processo de pesquisa.

Essa percepção se corrobora na conduta dos pesquisadores, uma vez que se constatou que, para a coleta de dados, foram adotados instrumentos diversos e algumas vezes complementares: análise documental ( 4 trabalhos), observações (um trabalho), questionários (4 trabalhos) e entrevistas ( 5 trabalhos). Os usos dos diversos instrumentos evidenciam, da parte dos pesquisadores, o interesse em fazer a ausculta dos atores diretamente envolvidos com os processos de mediação pedagógica, professores e tutores. Dentre os instrumentos, destaca-se a entrevista, que foi utilizada pela maioria dos pesquisadores, combinada ou não com outros recursos, como forma de privilegiar a comunicação em campo.

Constituindo-se em uma das técnicas mais utilizadas em trabalho de campo, a entrevista enseja a experiência de ouvir os sujeitos pesquisados, mas não se confunde com o espontaneísmo de uma interação ocasional. Diferentemente disso, guarda uma intencionalidade, que remete aos objetivos da pesquisa. Trata-se de situação em que a entrevista é tomada como:

Uma conversa a dois com propósitos bem definidos. Num primeiro nível, essa técnica se caracteriza por uma comunicação verbal que reforça a importância da linguagem e do significado da fala. Já, num outro nível, serve como um meio de coleta de informações sobre um determinado tema científico. (MINAYO, 2002, p. 57). 
Nessa perspectiva, nos diferentes trabalhos que se valeram dessa técnica, foram ouvidos, dentre outros, os professores ou professores tutores, reconhecidos como atores de relevância na cena educacional que se vale dos recursos digitais e nos programas/cursos da modalidade a distância.

\section{Considerações Sobre os Conteúdos Abordados}

Quanto aos conteúdos, os trabalhos mostraram a preocupação em considerar a importância assumida pelos professores e, em especial, pelos tutores nos diversos contextos de utilização das tecnologias digitais, envolvendo sobretudo práticas em EAD. É o que se evidencia nos excertos seguintes, constantes dos trabalhos cuja identificação se faz a partir da numeração adotada no quadro 2 e que se apresentam no quadro seguinte.

Quadro 3- Excertos que abordam a tutoria e o tutor nos trabalhos examinados

\begin{tabular}{|c|l|}
\hline Trabalhos & \multicolumn{1}{|c|}{ Excertos que abordam o tutor } \\
\hline T2 & $\begin{array}{l}\text { Urge estudos sobre os tutores que abordem aspectos deste sujeito [tutor] que } \\
\text { não se encontra devidamente reconhecido, ainda, como um profissional da } \\
\text { educação. Visando contribuir com esta lacuna, esta pesquisa vai se deter } \\
\text { especificamente sobre aspectos do seu trabalho. (Trabalho 2) }\end{array}$ \\
\hline T4 & $\begin{array}{l}\text { As responsabilidades do tutor são muito próximas daquelas que um professor } \\
\text { precisa realizar no seu exercício docente. Dessa forma, entende-se que a figura } \\
\text { do tutor na modalidade EAD pode servir para uma maior precarização do } \\
\text { trabalho no campo educacional. (Trabalho 4) }\end{array}$ \\
\hline T9 & $\begin{array}{l}\text { Apesar de serem em menor número, existem várias iniciativas institucionais no } \\
\text { Brasil que se pautam por esse paradigma que valoriza o trabalho da tutoria, } \\
\text { enquanto mediadora do processo ensino-aprendizagem, assumida pelo próprio } \\
\text { professor conteudista ou por outros professores especialmente contratados. } \\
\text { (Trabalho 9) }\end{array}$ \\
\hline
\end{tabular}

Fonte: Os autores.

O reconhecimento do papel relevante do tutor nas experiências em EAD faz-se presente nos estudos de muitos autores num contexto em que:

O progresso da EAD e o surgimento das novas mídias interativas alteram o panorama de ensino e aprendizagem, e nesse novo cenário tanto os alunos quanto os professores, e as próprias instituições, passaram a desempenhar novos e diferentes papéis. (MAIA; MATTAR, 2007, p. 83).

Os excertos em apreço evidenciam a importância conferida ao tutor no contexto dos trabalhos publicados, seja pela sua atuação mediadora no processo ensino-aprendizagem, 
seja pelo significado que assume na composição das relações de trabalho docente, em cujo contexto a presença desse ator pode, inclusive, sugerir a precarização da docência.

As competências para uso das tecnologias digitais, que perpassam o letramento dos sujeitos envolvidos, no entanto, não são tratadas de forma sistemática nem explícita nos diferentes trabalhos, conforme se evidencia no quadro seguinte:

Quadro 4- Excertos que abordam competências digitais nos trabalhos examinados

\begin{tabular}{|c|c|}
\hline Trabalhos & Excertos que abordam competências digitais \\
\hline T1 & $\begin{array}{l}\text { A partir destas manifestações dos entrevistados e analisando como eles se } \\
\text { referem à incorporação ou não das TIC no processo de orientação e as } \\
\text { mediações que estabelecem com o tempo e essas tecnologias, consideramos } \\
\text { importante analisar como esses envolvidos com a PG-não somente professores - } \\
\text { se relacionam com o tempo (Trabalho 1) }\end{array}$ \\
\hline T3 & $\begin{array}{l}\text { Raramente foram apontadas competências específicas do trabalho cotidiano da } \\
\text { sala de aula, quais sejam: saber elaborar um projeto; saber trabalhar em equipe; } \\
\text { saber planejar uma situação de aprendizagem; saber construir uma prova; saber } \\
\text { avaliar uma tarefa; saber se comunicar com a classe; saber elaborar uma } \\
\text { situação-problema; saber contextualizar; saber acompanhar o progresso dos } \\
\text { alunos; saber buscar recursos para implementar projetos de trabalho; saber } \\
\text { administrar o tempo do ensino; saber trabalhar com a heterogeneidade do } \\
\text { grupo-classe; saber preparar um seminário; saber improvisar, etc. (Trabalho 3) }\end{array}$ \\
\hline T5 & $\begin{array}{l}\text { Para responder ao desafio de integrar as tecnologias aos processos de formação, } \\
\text { a partir do viés da educação e comunicação, é preciso considerar as técnicas a } \\
\text { partir de duas dimensões indissociáveis: (i) como ferramentas pedagógicas } \\
\text { extremamente ricas e proveitosas para a melhoria e a expansão do ensino e (ii) } \\
\text { como objeto de estudo, fornecendo meios para o domínio das novas linguagens, } \\
\text { exigindo abordagens criativas, críticas e interdisciplinares (Trabalho 5) }\end{array}$ \\
\hline T6 & $\begin{array}{l}\text { O desafio, portanto, não é o acesso às TIC, mas recai sobre a necessidade de } \\
\text { avançar na qualidade do acesso: no caso da formação inicial de professores, isso } \\
\text { quer dizer pensar em como e para quê as TIC podem ser utilizadas nos } \\
\text { processos educativos, para que os atuais estudantes possam vivenciar } \\
\text { experiências de usos das TIC que } \\
\text { possibilitem ampliar sua futura atuação docente. (Trabalho 6) }\end{array}$ \\
\hline T7 & $\begin{array}{l}\text { A ausência de uma formação que permita aos licenciandos vivenciar o uso das } \\
\text { TDIC em situações de ensino-aprendizagem e refletir criticamente sobre o } \\
\text { mesmo e sobre o contexto no qual se realiza, pode resultar na adoção de } \\
\text { práticas de subutilização das TDIC. (Trabalho 7) }\end{array}$ \\
\hline T8 & $\begin{array}{l}\text { Parece ser consenso nos trabalhos analisados que, embora as TICs façam parte } \\
\text { da vida das pessoas, na escola, esses saberes ainda não estão sendo utilizados } \\
\text { de maneira efetiva e a formação ainda não potencializa a exploração de } \\
\text { possibilidades dos recursos tecnológicos para serem incorporados no processo } \\
\text { ensino aprendizagem, comprometendo sua implementação no contexto escolar. } \\
\text { (Trabalho 8) }\end{array}$ \\
\hline
\end{tabular}

Fonte: Os autores. 
Não se pode, a priori, asseverar que o letramento (digital) é ignorado pelos pesquisadores, tampouco que as competências nessa seara são olvidadas nas abordagens. É possível, inclusive, visualizar alusões a tais objetos no uso do vocábulo "mediações" (T1), "comunicar" (T3), em referências às atribuições dos tutores. Também é possível inferir a preocupação com essas competências, nas referências a "saber se comunicar com a classe" (T3); domínio das novas linguagens, exigindo abordagens criativas, críticas e interdisciplinares (T5); "que os atuais estudantes possam vivenciar experiências de usos das TIC que possibilitem ampliar sua futura atuação docente" (T6); "vivenciar o uso das TDIC em situações de ensino-aprendizagem e refletir criticamente sobre o mesmo" (T7).

Todavia, como demonstrado, as referências a competências na seara do letramento digital são tratadas de forma implícita, no bojo de outras preocupações, dentre elas: implicações das TIC para o trabalho do professor; tutoria e precarização do trabalho docente; (sub)utilização das TIC em contextos de ensino-aprendizagem etc.

\section{Considerações Finais}

O estudo apresentado evidencia, na circunscrição do corpus definido, certa incipiência das abordagens temáticas relativas ao tutor e às suas competências na seara do letramento e do letramento digital, na medida em que se reconhece recorrentemente a importância da tutoria nas interações em EAD, mas não se trata, de forma explícita e sistemática, as relações entre o letramento digital e a capacidade interacional do tutor.

Em geral os trabalhos objetos da presente análise abordam a tutoria, o tutor, as competências para o trânsito no ambiente virtual, mas silenciam ou mencionam en passant as questões atinentes a competências para interagir com os alunos, as quais implicam a mobilização de múltiplas estratégias discursivas. Tais estratégias requerem maior foco dos estudos sobre competências necessárias a atuação em tutoria, de modo a desvelar possibilidades e desafios, como contribuições para a diagnose sobre essa temática.

O aprofundamento de estudos nessa seara significará a possibilidade de melhor compreensão dos desafios inerentes ao ambiente hipetextual e multimodal instaurado pelas tecnologias digitais. Poderá contribuir também para a criação de instrumentos e programas de formação inicial e continuada de tutores, de modo a ampliar seu repertório 
e suas habilidades, no contexto do letramento digital, potencializando suas ações e interações nos processos em EAD.

\section{Referências}

BRASIL. Decreto 5.622, de 19 de dezembro de 2005. Regulamenta o artigo 80 da Lei no 9.394, de 20 de dezembro de 1996, que estabelece as diretrizes e bases da educação nacional. Disponível em: <http://www2.mec.gov.br/sapiens/portarias/dec5622.htm>. Acesso em: 10 jun. 2015.

CASTELLS, Manuel. A galáxia da internet: reflexões sobre a internet, os negócios e a sociedade. Rio de Janeiro: Jorge Zahar, 2003.

DIONISIO, Angela Paiva. Gêneros textuais e multimodalidade. In: KARWOSKI, Acir Mário et al. Gêneros textuais: reflexões e ensino. 4. ed. São Paulo: Parábola Editorial, 2011. p. 137-152.

FLICK, Uwe. Uma introdução à pesquisa qualitativa. Porto Alegre: Artmed, 2009.

GIORDAN, Marcelo. Uma perspectiva sociocultural para os estudos sobre elaboração de significados em situações de uso do computador na Educação em Ciências. 2006. 315 f. Tese (Livre Docência) - Faculdade de Educação, Universidade de São Paulo, São Paulo, 2006.

KLEIMAN, Ângela B. Os significados do letramento. São Paulo: Mercado de Letras, 1995.

KLEIMAN, Ângela B. Preciso "ensinar" o letramento? Não basta ensinar a ler e a escrever? Barão Geraldo: Cefiel/IEL/ Unicamp, 2010. (Coleção Linguagem e Letramento em Foco: linguagem nas séries iniciais).

KLEIMAN, Ângela B. Projetos de letramento na educação infantil. Campinas: Mercado de Letras, 2009.

LÉVY, Pierre. Cibercultura. 3. ed. São Paulo: Ed. 34, 2010.

MAIA, Carmem; MATTAR, João. $A B C$ da EAD: educação a distância hoje. São Paulo: Pearson, 2007.

MARCUSCHI, L. A. et al. Letramento e oralidade no contexto das práticas sociais eventos comunicativos. In: SIGNORINI, Inês (Org.). Investigando a relação oral/escrita e as teorias do letramento. Campinas: Mercado de Letras, 2001. (Coleção Ideias sobre Linguagem).

MILL, D. Sobre o conceito de polidocência ou sobre a natureza do processo de trabalho pedagógico na educação a distância. In: MILL, D.; OLIVEIRA, M. R. G.; RIBEIRO, L. R. C. (Org.). Polidocência na educação a distância: múltiplos enfoques. São Carlos: EDUFSCar, 2010. p. 23-40.

MINAYO, Maria Cecília de S. (Org.). Pesquisa social. 21. ed. Petrópolis: Vozes, 2002. 
ROJO, Roxane H. R. Letramento escolar, oralidade e escrita em sala de aula. Diferentes modalidades ou gêneros do discurso in letramento e oralidade no contexto das práticas sociais eventos comunicativos. In: SIGNORINI, Inês (Org.). Investigando a relação oral/escrita e as teorias do letramento. Campinas, SP: Mercado de Letras, 2001. (Coleção Ideias sobre Linguagem).

SOARES, Magda. Novas práticas de leitura e escrita: letramento na cibercultura. Educação e Sociedade, Campinas, v. 23, n. 81, p. 143-160, dez. 2002. Disponível em:

<http://www.scielo.br/pdf/es/v23n81/13935.pdf>. Acesso em: 9 abr. 2017.

STREET, B. V. Letramento sociais: abordagens críticas do letramento no desenvolvimento, na etnografia e na educação. São Paulo: Parábola Editorial, 2014.

STREET, B. V. Literacy in theory and practice. Cambridge: University Cambridge, 1984.

STREET, B. V. Social literacies: critical approaches to literacy in development, ethnography and education. Harow: Pearson, 1995.

XAVIER, Antônio Carlos dos Santos. Letramento digital e ensino. Disponível em: <https://www.ufpe.br/nehte/artigos/Letramento\%20digital\%20e\%20ensino.pdf>. Acesso em: 16 abr. 2015. 